\section{Ethical issues in Ph.D. training at the Politecnico di Milano}

\author{
Andrea Aliverti \\ Department of Electronics, Information \\ and Bioengineering, Politecnico di \\ Milano, Milan, Italy
}

\begin{abstract}
Ethical issues are fundamental in research, especially when multidisciplinary groups are involved. Ethical norms may protect human rights, animal welfare, compliance with the law, public health and safety. However, there are specific cases, which are not covered by rules and standards, and an interpretation is required. Based on these premises, since 5 years, the PhD School of the Politecnico di Milano has been offering $\mathrm{PhD}$ courses covering ethical issues, among which "Ethics in Research", briefly presented in this contribution.
\end{abstract}

\section{Introduction}

There are several reasons why it is important to identify ethical issues in research and to adhere to ethical standards. They promote the aims of research, namely knowledge, truth, and avoidance of errors. Research often involves a great deal of cooperation and coordination among many different people in different disciplines and institutions, therefore ethical standards promote the values that are essential to collaborative work, such as trust, accountability, mutual respect, and fairness. Ethical standards help to ensure that researchers can be held accountable to the public. For instance, recognizing possible research misconduct, conflicts of interest, tools for human subjects' protections, and animal care and use is necessary in order to make sure that researchers who are funded by public money can be held accountable to the public.

Ethical standards and norms promote a variety OF ISSUES INCLUDING social responsibility, human rights, animal welfare, compliance with the law, and public health and safety. Ethical lapses in research can significantly harm human and animal subjects, students, and the public.

Although codes, policies, and principals are very important and useful, like any set of rules, they do not cover every situation, they often conflict, and they require considerable interpretation.

\section{Results}

In order to address these issues, since five years the PhD School of the Politecnico di Milano offers, within the PhD courses portfolio, several courses. In particular in the course "Ethics in Research", throughout the presentation and discussion of many cases, the participants approach the problem of identifying ethical issues, analyse how to
Correspondence: Andrea Aliverti, Department of Electronics, Informatics and Bioengineering, Politecnico di Milano, Milan, Italy. E-mail: andrea.aliverti@polimi.it

Key words: $\mathrm{PhD}$ Training; ethical issues; research conduct; responsability.

Conference presentation: this paper was presented at the Second Centro 3R Annual Meeting - 3Rs in Italian Universities, 2019, June 20-21, University of Genoa, Italy.

Received for publication: 28 October 2019. Accepted for publication: 6 November 2019.

This work is licensed under a Creative Commons Attribution NonCommercial 4.0 License (CC BY-NC 4.0).

CC Copyright: the Author(s), 2019

Licensee PAGEPress, Italy

Biomedical Science and Engineering 2019; 3(s2):80 doi:10.4081/bse.2019.80

interpret, assess, and apply various research rules and how to make decisions and to act ethically in various situations. The course is aimed to make participants a) fully aware on how scientific and technological research have ethical implications; b) to identify ethical issues in specific research cases and procedures; c) to understand how the adherence to ethics standards is essential not only for respecting ethical values and fundamental rights, but also to increase quality and likely impact of research. 